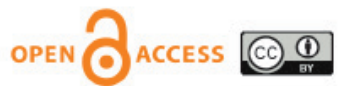

https://doi.org/10.47811/bhj.107

\title{
A rare case of plasma cell granuloma arising from facial nerve: A case report
}

\author{
Tika R. Adhikari ${ }^{1}$, Biren Pradhan ${ }^{2}$
}

\begin{abstract}
${ }^{1}$ Department of Otorhinolaryngology, Jigme Dorji Wangchuck National Referral Hospital, Thimphu, Bhutan
${ }^{2}$ Department of Pathology, Jigme Dorji Wangchuck National Referral Hospital, Thimphu, Bhutan
\end{abstract}

\begin{abstract}
Introduction: Plasma cell granuloma otherwise known as inflammatory myofibroblastic pseudo tumor is a rare disease of uncertain etiology. Occurance in temporal bone is very rare. They pose both diagnostic and therapeutic challenge. Case report: We present a 38-year-old male with a rare case of plasma cell granuloma arising from facial nerve. He has no other comorbidities except for a history of left ear modified radical mastoidectomy performed in 2002. This time he presented with mass in the ear canal with ear block and otorrhea for 1-month duration. Initial biopsy revealed granulation tissue. Computerised tomography scan revealed bony destruction with soft tissue mass. Diagnosis of recurrence of cholesteatoma was made for which he underwent Modified radical mastoidectomy under general anesthesia. Intraoperatively, there was soft tissue mass filling the mastoid and the middle ear and destruction of all ossicles. The mass was arising from facial nerve and there was bony dehiscence of facial nerve. The mass sent for histopathology revealed plasma cell granuloma. He recovered uneventfully with intact facial nerve and hearing level of 40 decibel. Conclusion: Ear canal polyp should not be avulsed as it may arise from facial nerve and any mass should be subjected to histopathological examination and should not be left as granulation tissue. This case supports the hypothesis of that plasmacell granuloma are psudotumour and with proper excision and post-operative steroids, there will be complete remission.
\end{abstract}

Keywords: Case report; Plasma cell granuloma; Pseudotumor.

\section{INTRODUCTION}

Plasma cell granuloma otherwise known as inflammatory myofibroblastic pseudo tumor is a rare disease of uncertain etiology. The World Health organization defines it "a distinctive lesion composed of myofibroblastic spindle cells accompanied by an inflammatory infiltrate of plasma cells, lymphocytes, and eosinophils"1. Recent theories suggest that it is post inflammatory or a local manifestation of a systemic inflammatory process such as IgG4-related sclerosis ${ }^{2}$. It was first described by Brunn in 1939 in lungs. Later in 1954 due to the destructive character it was named inflammatory myofibroblastic tumour by Umiker et al.

Extra pulmonary sites are uncommon and head and neck accounts for only $5 \%$ of extra pulmonary lesions with orbit being the most common site ${ }^{3}$. Skull base and temporal bone is an exceedingly rare site and in a review of literature, Ajibade et el ${ }^{4}$ described only 35 cases of inflammatory pseudotumour arising from skull base and temporal bone of which only 3 cases arose from facial nerve. In all the cases facial nerve was involved. Here we present an exceedingly rare case of plasma cell granuloma

\section{Corresponding author:}

Tika R. Adhikari

tikaram78@gmail.com arising from facial nerve which posed a diagnostic and therapeutic challenge, which subsequently was managed surgically and recovered without facial paralysis.

\section{CASE REPORT}

A 38-year-old male patient presented to Ear Nose and Throat out patient department (ENT OPD) with 1-month history of left ear fullness and otorrhea. He had undergone modified radical mastoidectomy of the same ear in 2002 for cholesteatoma. He has no other comorbidities. Clinical examination revealed a mass in the ear canal completely occluding the ear canal. The tympanic membrane and middle ear were not visualized. A punch biopsy was taken and he was treated with topical antibiotics-steroid ear drops. The initial histopathology report suggested a granulation tissue. Pure tone audiometry showed an air bone gap of 50dB. A high-resolution CT scan of temporal bone showed post surgery bony defect with mildly enhancing soft tissue mass filling the middle ear, mastoid and extending to external auditory canal with erosion of ossicles (Figure 1).

A clinical diagnosis of recurrence of cholesteatoma was made and revision MRM performed under general anesthesia. Intraoperatively, debulking of mass was done without avulsion. Mastoid and the middle was filled with the mass which was 


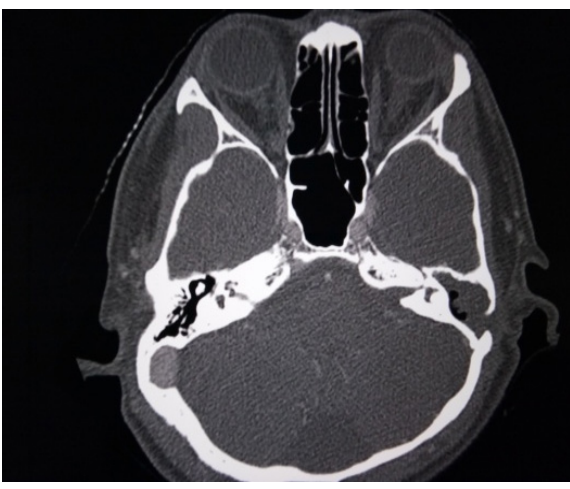

Figure 1a

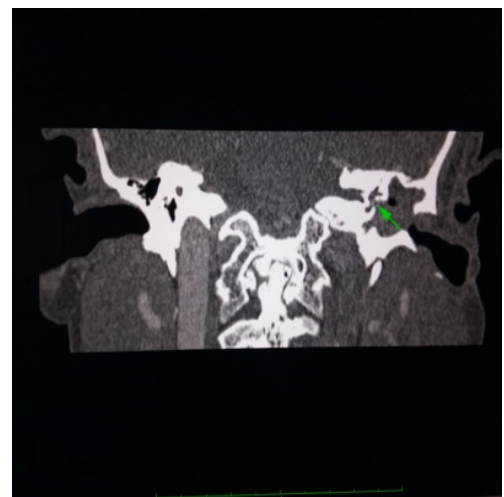

Figure 1b

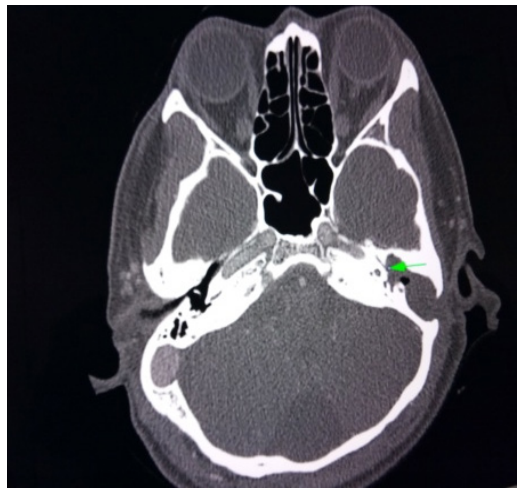

Figure 1c

Figure 1. CT scan of patient showing plasma cell granuloma involving facial nerve and bony erosion. a) Mass filling external canal and middle ear with missing ossicles. b) Coronal section showing mass involving facial nerve c) Axial cut showing mass involving facial nerve

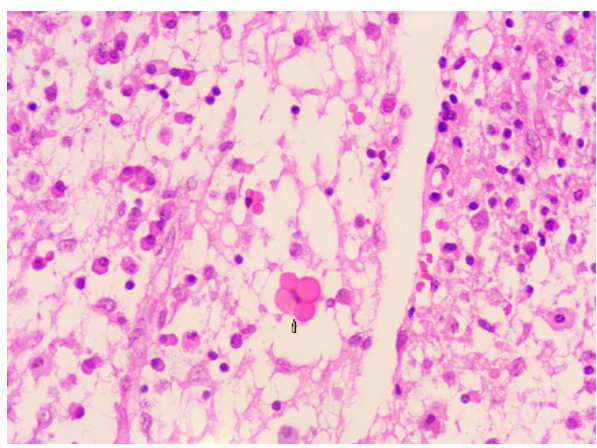

Figure 2a

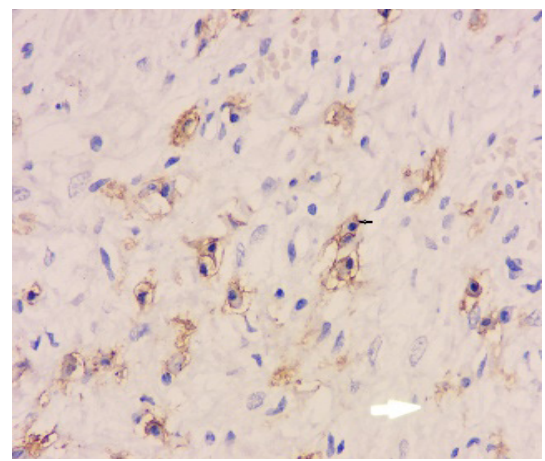

Figure 2d

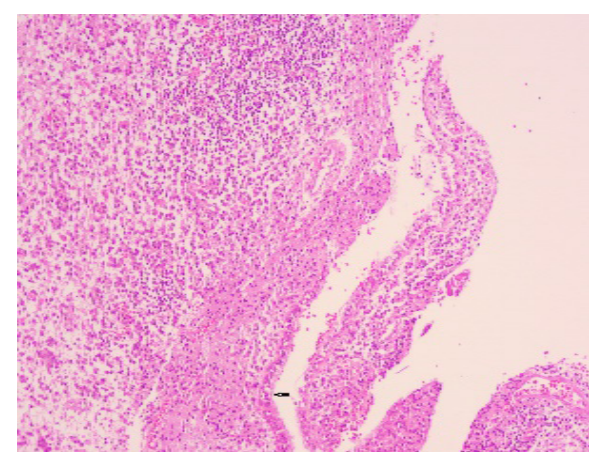

Figure $2 b$

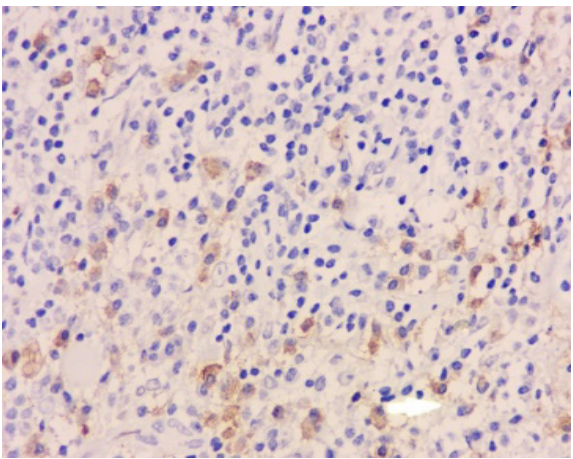

Figure 2e

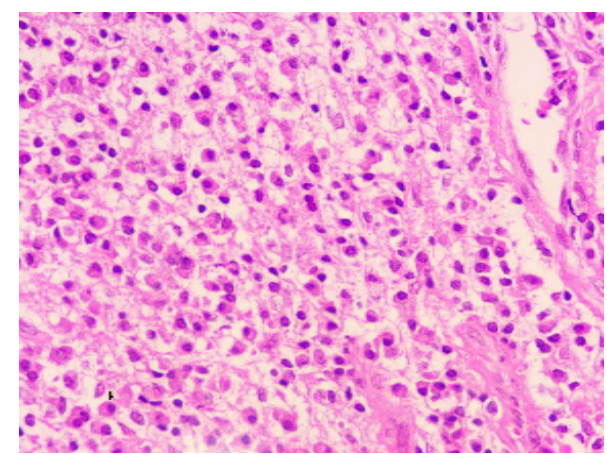

Figure 2c

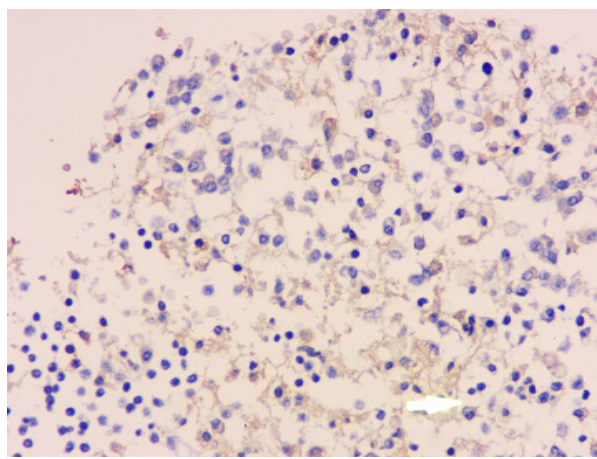

Figure $2 \mathrm{f}$

Figure 2. Histopathology of patient showing with immunohistochemical staining showing a) plasma cells b) Respiratory epithelium c) Russel body d) Plasma cell CD 38 stain(arrows) e) Lamda Immunostain f) Kappa Immunostain

subjected to histological examination. All the ossicles were eroded. The mass was arising from the facial nerve from its second genu. Adrenaline soaked cotton balls were used to gently scrape away the soft tissue from the facial nerve. There was no cholesteatoma matrix. The cavity was smoothened with a policing burr and obliterated with muscle flap and a wide meatoplasty done. Post operatively, recovery was uneventful and he did not have facial palsy.

Histopathology report was "infiltration by abundant benign plasma cells, mixed with lymphocytes and occasional polymorphonuclear leukocytes and eosinophils. Russell bodies with plasma cells are seen forming grape- like clusters. Immunohistochemical testing was done which showed CD38 positive for plasma cells and plasma cells with kappa and lambda light chains (Figure 2). A histopathological diagnosis of plasma cell granuloma (inflammatory pseudotumor) was made. Post operatively the patient was given tapering dose of prednisolone for a month.

Patient was followed up at 1 week, 1 month, 3months, 6 months and 1 year. The recovery was uneventful and did not show recurrence. At 1 year follow up he had pure tone average of $40 \mathrm{~dB}$. 


\section{DISCUSSION}

Plasma cell granuloma otherwise known as inflammatory myofibroblastic pseudo tumor is a rare disease of uncertain etiology. World Health organization defines it as "a distinctive lesion composed of myofibroblastic spindle cells accompanied by an inflammatory infiltrate of plasma cells, lymphocytes, and eosinophils"1.

The aetiopathogenesis is still unclear. One school of thought suggest it as an inflammatory disease (due to mixture of plasma cells, mixed inflammatory infiltrates, and absence of atypia) while others consider it as a neoplastic disease based on its association with ALK gene re-arrangement on chromosome $2 \mathrm{p} 23$, its recurrence, and metastasis ${ }^{5,6}$. Recent theories suggest that it is post inflammatory or a local manifestation of a systemic inflammatory process such as IgG4-related sclerosis².

Plasma cell tumour usually involves lung and extra pulmonary sites are uncommon. Head and neck accounts for only $5 \%$ of extra pulmonary lesions with orbit being the most common site $^{3}$. Skull base and temporal bone is an exceedingly rare site and in a review of literature, Ajibade et $\mathrm{el}^{4}$ described only 35 cases of inflammatory pseudotumour arising from skull base and temporal bone of which only 2 cases arose from facial nerve sheath.

Yanagihara et $\mathrm{al}^{7}$ described a case of recurrent facial palsy. Radiologically they diagnosed as a case of facial nerve neuroma. They removed the tumour through a combined transmastoid and middle cranial fossa approach, and performed nerve grafting. Final histopathological diagnosis was plasma cell granuloma.

Nick C Benton ${ }^{8}$ described the first case of plasma cell granuloma in the middle ear and the mastoid with intracranial extension. They diagnosed the case as primary maningioma of temporal bone. Post operatively the histopathological diagnosis was inflammatory pseudotumour. They gave postoperativeradiation after which there was no recurrence on subsequent follow up.

Joe B Wiseman ${ }^{9}$ described a 4-year-old child with tympanostomy tube with facial palsy. Imaging revealed soft tissue mass probably a tumour or effusion. Surgical decompression was planned. They performed two stage procedure to completely excise the mass. The facial nerve function returned to normal in subsequent follow up with no recurrence. Final diagnosis was inflammatory pseudotumour.

In all of the above reported cases, the preoperative and post operative diagnosis was not the same. Similar to our case they could diagnose the lesion only after surgery and histopathological confirmation. In our case also we had diagnosed as a recurrence of cholesteatoma but histopathological examination after the surgery confirmed it as inflammatory pseudotumour.

Furthermore, the management of inflammatory pseudotumour is controversial due to rarity of the disease. In the above 3 reported cases, $1^{\text {st }}$ underwent excision with nerve grafting, second underwent radiotherapy following excision of mass and third case removed the mass leaving facial nerve intact. We were also able to scrape the mass completely away from the facial nerve and had complete restoration of facial nerve function (House Brackman grade 1). According to H.S. Ong et $\mathrm{al}^{10}$, excision is the treatment of choice for head and neck inflammatory pseudotumour. However, an incomplete margin will lead to a $50 \%$ chance of recurrence ${ }^{11}$. Post operative steroids have been used to treat the incomplete excision with chemo radiation reserved for aggressive and inaccessible areas.

\section{CONCLUSIONS}

Inflammatory pseudotumours are rare in temporal bone and only 3 cases have been reported arising from facial nerve. It poses a diagnostic challenge and should be kept in mind when dealing with soft tissue mass in the middle ear behaving aggressively with bony destruction. Careful surgical excision without avulsion in any aural polyp will help prevent facial nerve injury with complete restoration of function. Post-operative steroids are helpful to residual lesion. Our case supports the hypothesis of inflammatory rather than neoplastic nature of plasma cell granuloma.

\section{REFERENCES}

1. Romeo S, Duim RAJ, Bridge JA, Mertens F, de Jong D, Dal Cin $\mathrm{P}$, et al. Heterogeneous and Complex Rearrangements of Chromosome Arm 6q in Chondromyxoid Fibroma. Am J Pathol. 2010;177(3):1365-76. [Full Text | DOI]

2. Ortlip TE, Drake VE, Raghavan P, Papadimitriou JC, Porter NC, Eisenman DJ, et al. Inflammatory pseudotumor of the temporal bone: A case series. Otol Neurotol. 2017;38(7):1024-31. [Full Text | DOI]

3. Kazantseva IA. Extrapulmonary inflammatory myofibroblastic tumor. Vol. 63, Arkhiv Patologii. 2001. p. 35-9.

4. Ajibade DV, Tanaka IK, Paghdal KV, Mirani N, Lee HJ, Jyung RW. Inflammatory pseudotumor (plasma cell granuloma) of the temporal bone. Ear, Nose Throat J. 2010;89(7):1-13. [Full Text | DOI]

5. Al-Humidi A, Al-Khamiss A. Inflammatory Myofibroblastic Tumor Arising in the External Ear: Unexpected Location. Int J Health Sci (Qassim). 2015;9(2):197-201. [Full Text]

6. Jung KH, Kim YW, So YK, Choi SI, Baek MJ. Inflammatory myofibroblastic tumor involving ear lobule. Auris Nasus Larynx [Internet]. 2012;39(6):631-3. [Full Text | DOI]

7. Yanagihara N, Segoe M, Gyo K, Ueda N. Inflammatory pseudotumor of the facial nerve as a cause of recurrent facial palsy: Case report. Am J Otol 1991; 12(3):199-202. [PubMed | Full Text] 
8. Benton NC, Korol HW, Smyth LT Jr. Plasma cell granuloma of the middle ear and mastoid. Case report. Ann Otol Rhinol Laryngol 1992; 101(1):92-4. [Full Text | DOI]

9. Wiseman JB, Arriaga MA, Houston GD, Boyd EM. Facial paralysis and inflammatory pseudotumor of the facial nerve in a child. Otolaryngol - Head Neck Surg. 1995;113(6):8268. [Full Text $\mid$ DOI]

10. Ong HS, Ji T, Zhang CP, Li J, Wang LZ, Li RR, et al. Head and neck inflammatory myofibroblastic tumor (IMT): Evaluation of clinicopathologic and prognostic features. Oral Oncol [Internet]. 2012;48(2):141-8. [Full Text | DOI]
11. Cho JG, Lee N, Yoo IO, Won Chae S. Inflammatory Myofibroblastic Tumors of the Middle Ear: An Unpredictable and Aggressive Disease. J Int Adv Otol. 2014;10(1):94-6. [Full Text | DOI] 